\title{
O Animal no Turismo: o caso de São Lourenço, MG, Brasil
}

Luís Carlos Araújo de Moraes

\section{Resumo}

Este trabalho tem como objetivo relatar experiência de visita à cidade de São Lourenço (MG, Brasil), tendo como foco o uso de animais na atividade turística. 0 trabalho traz uma breve discussão de moral e ética, e propõe, além de mudanças na visão do Estado sobre o animal a construção de uma nova ética para o turismo. Para isso, realizou-se uma pesquisa descritiva com estudo de caso e análise documental, viabilizada por uma visão participante, com inserção do pesquisador na realidade apresentada. Espera-se que cada visitante possa rever seus conceitos em relação à utilização do uso de charretes em localidades turísticas e que, a partir de tal fato, proponha uma moral constituinte que se transforme em moral constituída.

Palavras-chave: Ética e moral animal; Turismo; Sustentabilidade.

\begin{abstract}
Animals in tourism: the case of São Lourenço, MG, Brazil

This article's objective is to describe the experience of visiting São Lourenço city (MG), and its focus is on the use of animals in touristic activity. The article brings up a brief discussion on morals and ethics, and suggests, besides changes in the State's view on animals, the construction of a new ethic for tourism. In order to achieve this, a descriptive research was made, along with a case study and document analysis, enabled by a participative view with the insertion of the researcher in the presented reality. It is expected that each visitor may rethink their concepts towards the use of horsedrawn carts in touristic sites and, from that fact, to suggest a constitutive moral, which transforms itself into a constituted moral.
\end{abstract}

Keywords: Animal ethic and moral; Tourism; Sustainability.

\section{Resumen}

El animal en el turismo: el caso de São Lourenço, MG, Brasil

Este trabajo tiene como objetivo presentar la experiencia de visita a la ciudad de São Lourenço (MG, Brasil), teniendo como foco el uso de animales en la actividad turística. El trabajo trae una breve discusión de moral y ética, y propone, además de cambios en la visión del Estado sobre el animal, la construcción de una nueva ética para el turismo. Para eso, se realizó una investigación descriptiva con estudio de caso y análisis documental, viabilizada por una visión participante, con inserción del investigador en la realidad presentada. Se espera que cada visitante pueda volver a ver sus conceptos en relación a la utilización del uso de charretes en localidades turísticas y que, a partir de tal hecho, proponga una moral constituyente que se transforme en moral constituida.

Palabras clave: Moral y ética animal; Turismo; Sostenibilidad.

a. Mestre em Turismo e Meio Ambiente pelo Centro Universitário UNA. Belo Horizonte, Minas Gerais, Brasil. E-mail: lcambien@hotmail.com 
O homem, quando guiado pela ética,

éo melhor dos animais; quando sem ela,

éo pior de todos.

(Aristóteles)

\section{INTRODUÇÃO}

A palavra ética se origina de éthos, vocábulo grego para "modo de ser"; a palavra moral, por sua vez, se origina do latim mores, (costume). Enquanto moral é um conjunto de normas de conduta tidas como válidas de acordo com determinado tempo e lugar, a ética é a disciplina filosófica a partir da qual se refletirá sobre a moral.

Segundo Godoy e Trentin (2010), a moral manifesta-se apenas em sociedades humanas, em correspondência com as normas e relações socioculturais, cumprindo uma função determinada. Assim como a moral, o turismo também se desenvolve de acordo com as singularidades histórico-culturais, nas mais diversas localidades. Portanto, uma mudança na estrutura social local pode provocar uma mudança na ideia de moral adotada por determinado grupo social.

O turismo se apropriou do conceito de desenvolvimento sustentável na década de noventa e, com base na definição do Relatório Brundtland (1987), a Organização Mundial do Turismo (OMT), segundo Mourão (2000), define turismo sustentável como sendo aquele que

satisfaz as necessidades presentes dos turistas e das regiões receptoras, enquanto protege e realça as oportunidades para o futuro [...] é prospectivo e conduz a uma gestão de todos os recursos de forma a que as necessidades econômicas, sociais e estéticas possam ser preenchidas, enquanto se mantém a integridade cultural, os processos ecológicos essenciais, a diversidade biológica e os sistemas de suporte da vida animal e vegetal. (ORGANIZAÇÃO MUNDIAL DO TURISMO, 2003)

Para Krippendorf (2000), o turismo deve se desenvolver de modo a trazer a maior satisfação possível a todos os interessados: população local, turistas, e trade (desde que este não esteja ligado a inconveniências inaceitáveis). Assim, na atividade turística, a ética também cumpre um importante papel, pois sugere as ações que devem ser desempenhadas para o andamento positivo da atividade.

De acordo com Vieira (2006), a ética, para consolidar-se, pressupõe princípios que devem ser respeitados. E os atributos da respeitabilidade, embora restritos a pessoas e entes dotados de vida, estende-se também a nossos pertences, produtos e elementos da natureza que valorizamos.

\section{ÉTICA E MORAL ANIMAL}

A forma com que alguns indivíduos tratam os animais revela um especismo que, como o racismo e outros tipos de preconceitos, é fundamentalmente equivocado. Especismo pode ser definido como ato de discriminação arbitrária, ou pela atribuição de valores ou direitos diferentes àqueles que não pertencem a uma mesma espécie. Assim, se uma pessoa deseja conduzir a sua vida eticamente, não pode considerar somente os seus interesses, mas deve, igualmente, considerar os interesses de todos os outros afetados pelas suas ações. 
se um ser sofre, não pode haver justificativa moral para nos recusarmos a levar em consideração o seu sofrimento. Seja qual for a natureza do ser, o princípio da igualdade exige que o seu sofrimento conte o mesmo que o sofrimento semelhante de qualquer outro ser. [...] o racista viola o principio da igualdade ao dar mais peso aos interesses dos membros de sua própria raça. Da mesma maneira, o especista admite que os interesses de sua própria espécie suplantem os interesses mais fortes dos membros de outras espécies. 0 padrão é o mesmo nos dois casos. (SINGER, 2010, p. 34)

Regan (1991), que exige uma mudança no sistema que nos permite ver os animais apenas como recursos, compara a moral com um contrato, assinado pelas partes, em que direitos são reconhecidos. Para exemplificar, o autor cita o caso das crianças, que embora sejam incapazes de compreender a moralidade e, por conseguinte, incapazes de assinarem contratos, ainda assim têm seus direitos garantidos devido a razões sentimentais (despertadas pelo sentimento maternal/ paternal, por exemplo). Essa é a perspectiva que reconhece os chamados "deveres indiretos": "Desse modo, temos deveres em relação a essas crianças, deveres em consideração a elas. 0 mesmo vale para os animais" (REGAN, 1991. p. 79).

Nesse sentido, Singer (2010) corrobora com a citação de Regan quando critica certo princípio de igualdade humana que tem por referência supostas capacidades mentais superiores. 0 autor alega que, com base nesse critério, o princípio de igualdade poderia ser negado a certos humanos, como os recém-nascidos, por exemplo, que parecem não ser racionais ou autoconscientes, não possuindo, pois, sentido de moralidade nem de justiça. Contra a doutrina majoritária expressa em ideias tais como essa Singer entende que os animais, assim como os seres considerados incapazes, possuem direitos, ainda que estes precisem ser pleiteados por representantes reconhecidos como sujeitos, e não como objetos de direito.

Tal ponto de vista se apoia na ideia de senciência (capacidade que os animais possuem de sentir sensações e sentimentos). Filósofos como Primatt, Ryder, Linzey, Singer e Regan afirmam que o reconhecimento da senciência pelos humanos determina sua imparcialidade de pensamento capaz de nos remeter a um juízo ético que, por sua vez, nos levará a ter uma consciência moral em relação aos animais, mudando nossas atitudes para com eles. Para os autores, portanto, a senciência determina a inclusão da relação entre humanos e animais no âmbito moral.

Primatt (1992), baseando-se na ética da reciprocidade e no experimento mental por analogia, propõe em uma de suas teses: "trata teu cavalo como desejarias que teu dono te tratasse, se fosses tu um cavalo". Quando seres humanos trabalham somente em troca de comida e moradia, chamamos a isso de escravidão. Seria diferente com os animais?

Bentham (1970) reafirma o pensamento de Primatt ao afirmar que a questão não é se os animais são capazes de raciocinar nem se são capazes de falar, mas, sim, se são capazes de sofrer.

\section{TURISMO SUSTENTÁVEL NA CONSTRUÇÃo DE UMA NOVA ÉTICA}

A sustentabilidade envolve fenômenos sociais e econômicos, como nos mostra o histórico das discussões dos problemas ambientais elencados em vários documentos: o Relatório Brundtland, a Carta da Terra, a Declaração do Milênio da ONU, a Declaração dos Direitos Humanos, a Agenda 21, entre outros. 
Tais documentos tiveram grande impacto, influenciando as normas que regem a sociedade, o que, por sua vez, influenciou o modo de produção e as relações do homem com o ambiente e consigo mesmo, suscitando, assim, reflexos no desenvolvimento da atividade turística.

Dessa forma, o turismo se apropriou do conceito de desenvolvimento sustentável, e diversos pesquisadores se manifestaram a respeito, citando normas de conduta que envolvem turistas e residentes e suas relações com o ambiente onde a atividade se desenvolve. Entretanto, a consideração e o respeito com os animais, atores mais fracos foram ignorados, indo de encontro às normas estabelecidas pelas legislações pertinentes.

Romero (2004, p. 6) apresenta a dimensão ética da sustentabilidade argumentando que

a forma pela qual a sociedade usa o meio ambiente é decorrente de sua visão sobre o mundo e sobre o status do homem em relação às demais formas de vida. Assim, a sociedade formula seus conceitos de justiça ambiental relativos às formas de vida não humanas, às gerações futuras e às gerações atuais, atribuindo valor e tomando decisões sobre o meio ambiente.

O Código de Ética Mundial para o Turismo percebe que o turismo responsável passa pela compreensão e a promoção dos valores éticos comuns da humanidade, em um espírito de tolerância e respeito à diversidade, aos pensamentos filosóficos e morais. Portanto, entende-se que o planejamento do turismo deve considerar e respeitar também os animais que fazem parte, direta ou indiretamente, da atividade turística.

Nesse contexto é inadmissível que a atividade turística continue a desconsiderar os animais que utiliza, por exemplo, para puxar charretes, com argumento de que se trataria de uma atividade tradicional ou, em termos economicistas do sustento de famílias dependentes do turismo. Tal discurso se baseia no argumento prosaico de que os fins justificam os meios. Fins éticos, porém, exigem meios éticos.

\section{O CASO de sÃo LOURENÇo}

São Lourenço (MG), com cerca de 45 mil habitantes, é uma das cidades mais movimentadas do Circuito das Águas. Com a população flutuante, nos feriados prolongados e temporada, a cidade chega a receber 100 mil pessoas (SÃO LOURENÇO, 2016). 0 mapa turístico disponibilizado pelo próprio Convention \& Visitors Bureau (2015) e facilmente encontrado nos meios de hospedagens traz impresso o anúncio do passeio de charretes com o seguinte texto:

Um dos passeios mais tradicionais da São Lourenço é o passeio de charretes disponível no centro da cidade, próximo ao Parque das Águas. No passeio, é possível visitar diversos pontos turísticos, fábricas de malhas, fábricas de doce. Possui mini charretes e bodinhos para as crianças também aproveitarem. (grifo nosso)

Não se pode ignorar a falta de consideração de tutores que excedem em abusos contra seus cavalos e demais animais que se prestam a puxar as charretes. Com raríssimas exceções, os animais trabalham o dia todo, e, às vezes, também no período noturno, sob pressão: sem comer, beber ou até descansar. Os apetre- 
chos que os prendem às charretes incompatíveis com condições de conforto e segurança, causam incômodos e ferimentos aos animais. Além disso, os animais ficam expostos às intempéries, como sol forte, chuva e frio. Como resultado, o que se observa são animais tristes, desnutridos e subjugados.

Não obstante o argumento significativo dos charreteiros, que afirmam tratar-se de uma atividade tradicional da cidade e que, por isso, não pode ser modificada, é preciso destacar que os tempos são outros, o momento sociocultural e ambiental também, e não se pode comparar uma atividade do século passado com as atividades de hoje. A sociedade, a economia, a cidade e, sobretudo a legislação são outras. Além disso, existem outras opções para a realização de passeios que não demandam o uso de animais.

A despeito de ser o turismo a principal fonte de renda dos cidadãos, e haver certa preocupação, relatada em vídeos divulgados na internet, dos visitantes com os animais, a maior parte dos turistas continua a andar de charretes, e o serviço continua a ser prestado em detrimento do bem-estar dos animais.

Cabe ressaltar que as charretes já são proibidas em diversas cidades tanto do exterior como aqui do Brasil. Na Ilha de Paquetá (RJ), por exemplo, as charretes foram substituídas por veículos elétricos. Assim todos ganham: o visitante que quer conhecer a cidade, utilizando para isso um meio de transporte considerado ecologicamente correto; os trabalhadores, que não irão deixar de trabalhar e que ganharão mais, pois não terão gastos com o animal (alimentação, remédios, vacinas, ferragens, cochos, estábulos etc.); e os animais, que, no caso da Ilha de Paquetá, foram para um sítio em Teresópolis onde vivem livres na natureza.

\section{O ESTADO E O ANIMAL}

Rodrigues (2010) cita diversos diplomas legislativos relacionados à proteção dos animais no âmbito internacional e nacional, cada qual com suas especificidades. A Carta de Terra, por exemplo, apresenta entre seus princípios o respeito à Terra e à vida em toda sua diversidade e o tratamento de todos os seres vivos com respeito e consideração. Já a Constituição Federal, em seu artigo 225, inciso VII, incumbe ao poder público "proteger a fauna e a flora, vedadas, na forma da lei, as práticas que coloquem em risco sua função ecológica, provoquem a extinção de espécies ou submetam os animais a crueldade" (BRASIL, 2015), reconhecendo, pois, que o animal é um ser senciente, capaz de sentir dor e de sofrer. Logo, conclui-se que o animal não pode ser considerado uma coisa ou objeto.

Esse foi o entendimento, por exemplo, dos ministros do Supremo Tribunal Federal, que consideraram que a atividade da vaquejada, por exemplo, impõe sofrimento aos animais e, portanto, fere princípios constitucionais descritos na lei supracitada, ficando proibida, pois, a prática da atividade no estado do Ceará, em decisão que concedeu jurisdição para o restante do país.

Um mês após a decisão, porém, a Comissão de Educação, Cultura e Esporte do Senado aprovou no dia 1o de novembro de 2016 o projeto de lei que eleva a vaquejada à condição de manifestação cultural nacional e patrimônio cultural imaterial do país. Na ocasião, manifestantes favoráveis ao projeto, ocuparam o gramado central da Esplanada dos Ministérios, em Brasília, alegando que se trata de uma atividade econômica importante, que movimenta cerca de $\mathrm{R} \$ 14$ milhões por ano. 
Cabe frisar que, segundo o Decreto Federal no 3.551/2000, que institui o registro de bens culturais de natureza imaterial que constituem patrimônio cultural brasileiro, existem etapas a serem cumpridas antes que uma manifestação seja declarada um bem cultural de natureza imaterial (BRASIL, 2000). No caso da vaquejada, o procedimento não foi obedecido.

Retomando a análise legal, a lei de crimes ambientais (BRASIL, 1998), em seu artigo 32, tipifica o crime contra fauna para quem "Praticar ato de abuso, maus-tratos, ferir ou mutilar animais silvestres, domésticos ou domesticados, nativos ou exóticos", prevendo aos infratores "pena de detenção, de três meses a um ano, e multa". Também incide nas penas "Quem, de qualquer forma, concorre para a prática dos crimes previstos", bem como a autoridade que "sabendo da conduta criminosa de outrem, deixar de impedir a sua prática, quando podia agir para evitá-la" (BRASIL, 1998). Da mesma forma, A Lei das Contravenções Penais (Decreto no 3.688/1941), em seu artigo 64, faz referência a prisão simples, de dez dias a um mês, ou multa, para aquele que "Tratar animal com crueldade ou submetê-lo a trabalho excessivo" (BRASIL, 1941). Caso o animal seja exposto ao público, aplica-se a pena aumentada pela metade.

O Plano Diretor de São Lourenço, em seu artigo 144, relata a proibição de:

I - transportar em animais ou em veículos de tração animal, carga de peso superior às suas forças;

II - fazer trabalhar ou abandonar animais feridos, doentes, extenuados, enfraquecidos ou extremamente magros;

III - martirizar animais para deles alcançar esforços excessivos;

IV - conduzir animais em qualquer posição anormal que lhes possa ocasionar sofrimento;

V - amontoar animais em depósitos com espaço insuficiente ou sem água, ar, luz e alimentos;

VI - empregar arreios que possam constranger, ferir ou magoar o animal, ou usá-los sobre partes feridas, contusões ou chagas;

VII - praticar todo e qualquer ato, mesmo não especificado neste Código, que possa acarretar violência e sofrimento para o animal. (SÃO LOURENÇO, 2016)

Não obstante a existência de diversas legislações ambientais, assim como da responsabilidade pela atividade turística desenvolvida em território de sua competência, nota-se que o executivo local parece não tomar providência alguma a fim de solucionar o problema. Cabe destacar, ainda, o Decreto no 24.645/1934, que estabelece, em seu artigo 1ํㅡㄹ que todos os animais existentes no país são tutelados do Estado (BRASIL, 1934).

\section{CONSIDERAÇÕES FINAIS}

Considerando que a sustentabilidade turística está calcada em princípios sociais, econômicos, culturais, políticos e ambientais, entende-se que, se todos estiverem empenhados na construção de uma nova ética, que modifique a visão sobre o relacionamento do homem com as demais formas de vida, talvez sejamos capazes de propor uma moral constituinte, criada a partir da experiência vivida, que influencie a moral constituída. Assim, se cada visitante se recusar a andar nas charretes, seus proprietários terão que rever seus conceitos, se adaptando a essa nova realidade. 
Em relação à aplicação das legislações existentes (federais, estaduais ou municipais) no destino estudado, conclui-se que a atuação do poder público mostrou-se ineficaz em dar qualquer proteção aos animais explorados pela atividade turística, fato que pode ser atribuído à inexistência de qualquer órgão de fiscalização que atue especificamente com esse tipo de caso e que faça cumprir as legislações.

Há alternativas viáveis, como bicicletas, veículos e triciclos com tração mecânica, ou meios que utilizam fonte de energia ecologicamente correta, como carros elétricos, por exemplo, que podem ser usados pelos visitantes. Por que, então, usar charretes puxadas por animais, e com sacrifícios destes em nome de uma tradição e um inaceitável conservadorismo cultural? 0 tempo atual exige mudanças de paradigma, e não devemos, em detrimento dos seres vivos que sofrem em nome da atividade turística, ficarmos presos a valores que antecedem ao advento dos veículos a vapor.

Diante do exposto, o grande desafio é conscientizar os visitantes e a sociedade quanto ao respeito a toda forma de vida, não cabendo ao ser humano maltratar os animais, seja de que espécies forem.

Para finalizar, a Figura 1 reflete tudo aquilo que foi descrito neste trabalho. Que a sua dor seja a nossa dor.

Figura 1 - A tua liberdade

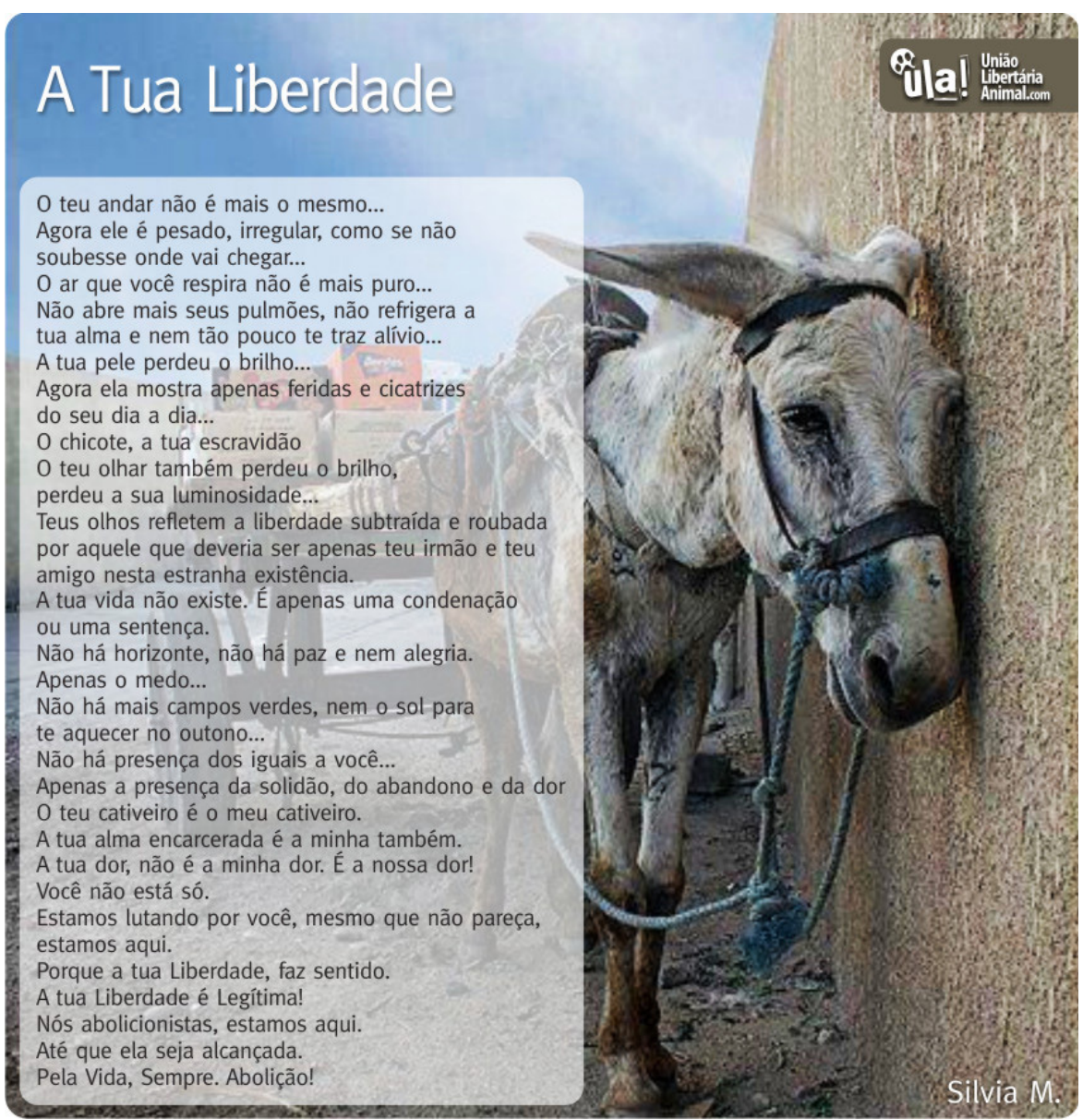

Fonte - Silvia M. ${ }^{1}$

1. Disponível em: <http://www.uniaolibertariaanimal.com/site/index.php/faces-da-exploracao/ instrumento/transporte.html>. 


\section{REFERÊNCIAS}

BENTHAM, J. An introduction to the principles of morals and legislation. London: The Athlone Press, 1970.

BRASIL. Casa Civil. Lei no 9.605, de 12 de fevereiro de 1998. Dispõe sobre as sanções penais e administrativas derivadas de condutas e atividades lesivas ao meio ambiente, e dá outras providencias. Diário Oficial da República Federativa do Brasil. Brasília, DF, 13 fev. 1998. Disponível em: <http://bit.ly/1La6hQT>. Acesso em: 21 mar. 2017.

. Constituição da República Federativa do Brasil: texto constitucional promulgado em 5 de outubro de 1988, com as alterações adotadas pelas emendas constitucionais no 1/1992 a 88/2015, pelos decretos legislativos no 1 a 6/1994. 47. ed. Brasília: Câmara dos Deputados, Câmara, 2015.

Decreto no 24.645 de 10 de julho de 1934. Estabelece medidas de proteção aos animais. Diário Oficial da República Federativa do Brasil. Rio de Janeiro, 11 jul. 1934. Disponível em: <http://bit.ly/1xYbAQ8>. Acesso em: 31 mar. 2017.

. Decreto no 3.551 de 4 de agosto de 2000. Institui o Registro de Bens Culturais de Natureza Imaterial que constituem patrimônio cultural brasileiro, cria o Programa Nacional do Patrimônio Imaterial e dá outras providências. Diário Oficial da República Federativa do Brasil. Brasília, DF, 4 ago. 2000. Disponível em: <http://bit.ly/2e2g6s0>. Acesso em: 31 mar. 2017.

Decreto no 3.688 de 3 de outubro de 1941. Lei das Contravenções Penais. Diário Oficial da República Federativa do Brasil. Rio de Janeiro, 3 out. 1941. Disponível em: <http://bit.ly/1U2PfLP>. Acesso em: 21 mar. 2017.

GODOY, K. E; TRENTIN, F. Ética e turismo. Rio de Janeiro: Fundação Cecierj, 2010. v. 1.

KRIPPENDORF, J. Sociologia do turismo: para uma nova compreensão do lazer e das viagens. São Paulo: Aleph, 2000.

LINZEY, A. The theos-rights of animals. In: REGAN, T.; SINGER, P. Animal rights and human obligations. New Jersey: Prentice Hall, 1989. p. 134-138.

ORGANIZAÇÃO MUNDIAL DO TURISMO. Guia de desenvolvimento do turismo sustentável. Porto Alegre: Bookman, 2003.

PRIMATT, H. A dissertation on the duty of against mercy and the sin of cruelty to brute animals. Fontwell/Sussex: Centaur Press, 1992.

REGAN, T. The case for animal rights. In: BAIRD, R. M.; ROSENBAUN, S. E. (Org.). Animal experimentation: the moral issues. New York: Amherst, 1991. p. 77-88.

RODRIGUES, D. T. Observações sobre a proteção jurídica dos animais. Ciência Veterinária nos Trópicos, Recife, v. 13, p. 49-55, 2010. Suplemento 1.

ROMERO, M. A. et al. Indicadores de sustentabilidade dos espaços públicos urbanos: aspectos metodológicos e atributos das estruturas urbanas. In: SEMINÁRIO A QUESTÃO AMBIENTAL URBANA, 2004. Anais... Brasília: UnB, 2004.

RYDER, R. D. Speciesism. In:___. Victims of science: the use of animals in research. London: Centaur Press, 1983, p. 1-14.

SÃO LOURENÇO. Convention \& Visitors Bureau. Mapa Turístico. São Lourenço, 2015.

SÃO LOURENÇO. Prefeitura Municipal. Lei Municipal no 1.811. Institui o Código de Posturas do Município de São Lourenço. Plano Diretor. São Lourenço, 8 fev. 1993. Disponível em: <http://bit.ly/2mMt11t >. Acesso em: 21 mar. 2017.

SINGER, P. Libertação animal. Porto Alegre: Lugano, 2010. 
. The significance of animal suffering. In: BAIRD, R. M.; ROSENBAUM, S. E. (Eds). Animal experimentation: the moral issues. Amherst: Prometheus Books, 1991. p. 57-66.

VIEIRA, R. B. C. A ética no turismo. Revista Turismo, 2006. Disponível em: <http://bit. ly/2nGRhqY>. Acesso em: 1 jun. 2016.

Recebido em: 01/06/2016

Aprovado em: 10/03/2017 